\title{
Nuances of restoration of lumbar lordosis using an MIS anterior column release versus posterior 3-column osteotomy
}

\author{
Michael S. Virk, MD, PhD, and Praveen V. Mummaneni, MD \\ Department of Neurological Surgery, University of California, San Francisco, California
}

\section{$\mathrm{L}$} EVEQUE et al. ${ }^{1}$ present a comparison of pedicle subtraction osteotomy (PSO) to lateral interbody fusion and anterior column realignment (LLIF-ACR) for restoring lumbar lordosis in patients with spinal deformity. This is a retrospective chart review from a single institution, spanning 2010-2015, that generated 14 patients in the PSO group and 13 in the LLIF-ACR group. Patients who had a PSO were excluded if they had a preexisting fusion of more than 4 levels or if there was an additional lateral approach incorporating hyperlordotic grafts (angulation $>15^{\circ}$ ).

There are several intra- and perioperative issues to note. The primary finding is that equivalent correction of lumbar lordosis was achieved in the LLIF-ACR cohort with approximately $50 \%$ of the blood loss of the PSO cohort $(1466 \mathrm{ml}$ vs $2910 \mathrm{ml}$ for the PSO group, $\mathrm{p}<0.01)$. Patients who received antifibrinolytic agents were excluded from this study. The total operative time and length of stay were equivalent in the 2 groups. Where procedures for patients in either group were staged, estimated blood loss and operative time were combined to include the net total.

The authors use pelvic incidence-lumbar lordosis (PILL) ratios as the primary spinopelvic parameter to compare the groups pre- and postoperatively. They reported the same degree of correction in the PSO and LLIF-ACR groups. They also noted that lordosis correction is equivalent to $54 \%$ of the hyperlordotic cage angle. Thus, when $30^{\circ}$ cages are used, approximately $15^{\circ}$ of correction was achieved on average.

This paper has a few shortcomings. There are no standardized patient-reported outcomes. There is no fusion evaluation. A third-party observer should ideally be used to assess bony fusion by evaluating radiographs or a CT scan. There was no preoperative assessment of bone quality in the patients; we typically assess osteoporosis with a preoperative bone density study in patients who are having multilevel deformity correction surgery. Finally, the PSO group was followed for 25.5 months, whereas the LLIFACR group was followed for 13.2 months. This may create a bias when evaluating outcomes such as "reoperation for pseudarthrosis" since it is not yet known if the LLIF-ACR patients will need late revision surgery at 1-2 years after surgery, as their duration of follow-up is short.

Restoring lumbar lordosis is one of the primary goals of treating patients with adult spinal deformity characterized by sagittal imbalance. Anterolateral approaches including lateral interbody techniques with anterior longitudinal ligament (ALL) release and hyperlordotic graft placement have emerged as a new option. These "minimally invasive techniques" are being suggested as potential alternatives to PSO in selected patients. The complications associated with PSO are now well documented, but we do not yet know the full complication profile for LLIF-ACR ${ }^{2}$ There is the potential for iliac vessel injury with the LLIF-ACR, and this is not typically a complication associated with PSO. However, comparison studies are sparse in the literature. Algorithms outlining a rational approach to addressing spinal deformity through a variety of minimally invasive and open techniques are now becoming more sophisticated. ${ }^{3}$ Not all patients are candidates for the minimally invasive correction of spinal deformity, and patient selection is the key.

The authors are to be commended for contributing important data that facilitate our understanding of these 2 strategies.

https://thejns.org/doi/abs/10.3171/2017.6.FOCUS17390 


\section{References}

1. Leveque JC, Yanamadala V, Buchlak QD, Sethi RK: Correction of severe spinopelvic mismatch: decreased blood loss with lateral hyperlordotic interbody grafts as compared with pedicle subtraction osteotomy. Neurosurg Focus 43(2):E15, 2017

2. Mummaneni PV, Dhall SS, Ondra SL, Mummaneni VP, Berven S: Pedicle subtraction osteotomy. Neurosurgery 63 (3 Suppl):171-176, 2008

3. Mummaneni PV, Shaffrey CI, Lenke LG, Park P, Wang MY, La Marca F, et al: The minimally invasive spinal deformity surgery algorithm: a reproducible rational framework for decision making in minimally invasive spinal deformity surgery. Neurosurg Focus 36(5):E6, 2014

\section{Disclosures}

Dr. Mummaneni reports a consultant relationship with DePuy Spine and Stryker Spine; direct stock ownership in Spinicity ISD; receipt of royalties from DePuy Spine, Thieme Publishing, and Springer Publishing; receipt of honoraria from Globus and AOSpine; grant receipt from AOSpine; and receipt of support for clinical or research efforts from ISSG. 